\title{
A IMPORTÂNCIA DA LUTA DOS MOVIMENTOS FEMINISTAS NO DESENVOLVIMENTO DA TIPIFICAÇÃO DO FEMINICÍDIO E NA BUSCA POR IGUALDADE ENTRE OS GÊNEROS
}

\author{
Claudine Rodembush Rocha ${ }^{1}$ \\ Henrique Alexander Grazzi Keske ${ }^{2}$
}

\section{RESUMO}

O presente artigo apresenta um breve histórico do que denomina de ativismo social feminino, enfatizando que os direitos de igualdade, concretizados em nosso ordenamento, se deram em função dessa luta, de forma que se revestem da condição de verdadeiras conquistas e não meras concessões. Para tanto, através de pesquisa bibliográfica, se analisa a lei tipificadora e/ou qualificadora do feminicídio, inserida nesse contexto de luta de tais movimentos, revestindo-se, assim do caráter de ato simbólico, político e jurídico para o enfrentamento da violência contra a mulher pela sua simples condição de ser mulher.

Palavras-chave: Ativismo Social, Feminicídio, Gênero, Igualdade e Violência.

\section{THE IMPORTANCE OF THE FIGHTING OF FEMINIST SOCIAL MOVEMENTS IN THE DEVELOPMENT OF THE FEMINICITY AND IN THE SEARCH FOR EQUALITY BETWEEN GENDERS}

\begin{abstract}
This article presents a brief history of the feminine social activism, emphasizing that the equality rights, concretized in our ordering, which were given in function of this struggle, being faced with the condition of real achievements and not mere concessions. Through a bibliographical research, it analyzes the typifying and/or qualifying law of feminicide, inserted in this context of struggle of these movements, covering itself of symbolic, political and juridical act for the confrontation of the violence against the woman by its simple condition of being woman.
\end{abstract}

Keywords: Social Activism; Feminicide; Gender; Equality; Violence.

\section{INTRODUÇÃO}

Duas são as motivações básicas para a escritura do presente artigo; sendo que a primeira delas diz respeito a uma das mais inquietantes realidades sociais vivenciadas em nosso país, ou seja, à trágica situação da violência contra a mulher, que coloca o Brasil entre os países do mundo que apresenta os mais elevados patamares de agressões sofridas pelas

\footnotetext{
${ }^{1}$ Doutora em Direito pela Universidade de Burgos-Espanha, Mestre em Direito pela Universidade de Santa Cruz do Sul - UNISC, Pós-graduada em Demandas Sociais e Políticas pela Universidade de Santa Cruz do Sul UNISC, Advogada, Professora do Curso de Direito da Faculdade Estácio do Rio Grande do Sul. E-mail: claudinerodembusch@yahoo.com.br.

${ }^{2}$ Doutor em Filosofia pela Universidade do Vale do Rio dos Sinos - UNISINOS, Mestre em Filosofia pela Pontifícia Universidade Católica - PUC/RS. Advogado. Professor de Direito da Universidade Feevale. E-mail: henriquek@feevale.br
} 
mulheres pela sua simples condição de serem mulheres. Tal fato social terrível, provavelmente, teria motivado o legislador pátrio a intensificar o enfrentamento do problema, através da tipificadora do feminicídio. Entretanto, o que se pretende, aqui, é partir do pressuposto de que antes dessa medida, outra lei emblemática, a Lei Maria da Penha, fora instituída, ainda que por pressão de Instituições Internacionais, como o Comitê Interamericano de Direitos Humanos, com a mesma finalidade e demonstrou exatamente o oposto, ou seja, o aumento do número de casos dessa violência espúria. Nesse sentido, porém, o que se quer destacar é que, em verdade, o que se vivenciou e vivencia com esse primeiro enfrentamento, não se refere, exatamente, a um aumento de casos, senão que, através dessa Lei inicial, o que se fez foi dar visibilidade ao problema, que, um pouco antes, começa a sair do obscurantismo a que estava relegado, por outra medida emblemática, que o artigo também destaca, que é o surgimento das Delegacias de Defesa da Mulher.

Da mesma forma, a seguinte motivação trata de, igualmente, se retirar dessa obscuridade o fato de que tanto a Lei Maria da Penha, como agora, a qualificadora do feminicídio sejam, bem como todos os demais direitos estabelecidos no direito pátrio em relação à mulher, ou à condição feminina, não meras concessões de legisladores, poderes públicos e/ou instituições, mas de uma verdadeira luta feminina que já atravessa séculos, constituindo-se, outrossim, em verdadeiras conquistas de movimentos sociais organizados, que se empenharam, decididamente, na busca por essa igualdade de direitos. O que se quer, portanto, ressaltar, é que tais direitos não se teriam concretizado como leis positivas, sem a permanente luta desses movimentos sociais reivindicatórios - essa é a pretensão: dar o crédito dessa conquista às próprias mulheres, através de um ativismo próprio.

Por outro viés, não se parte da ilusão, nem se pretende afirmar que a radicalização dos processos punitivos, via lei penal mais dura, como a qualificadora do feminicídio, venha a resolver o problema da violência sofrida, tristemente, ainda, pelas mulheres, mas se pretende ressaltar o valor dessa tipificação, enquanto ato simbólico, político e, logo, jurídico, de que essa medida legislativa se reveste. Tal problema trata-se, sem dúvida de uma de nossas maiores mazelas sociais, cujo enfrentamento não se resolve somente com o recrudescimento da lei penal, mas por uma mudança verdadeiramente estrutural dessa mesma sociedade e, porque não, da necessidade de políticas públicas mais eficazes, focadas na resolução, ou, pelo menos, em minimizar o problema. 
Entretanto, o marco regulatório se nos afigura como de fundamental importância, no sentido de associar, de maneira explícita, as ações sociais necessárias, com as políticas públicas e o papel legislativo do Estado e do Direito, no sentido de se consolidar, concretamente, a definição constitucional de nosso país como um Estado Democrático de Direito. Nesse sentido é que apresentamos um breve histórico do pioneirismo das mulheres em seu ativismo, tanto em nível internacional, quanto em nosso país, bem como a validade da tipificadora e/ou qualificadora do feminicídio, enquanto necessário marco regulatório tendente a dar visibilidade, criar e aprimorar formas de investigar e julgar, para enfim, prevenir, coibir e punir tal prática odiosa de assassinato de mulheres.

\section{BREVE SITUAÇÃO HISTÓRICA: MOVIMENTOS SOCIAIS FEMINISTAS}

De pronto, e com a finalidade de tratarmos das questões históricas em relação ao surgimento dos movimentos sociais reivindicatórios dos direitos das mulheres, devemos ter presente a afirmação de Simone de Beavouir (1970, p.167): “ toda a história das mulheres foi feita pelos homens"; ou seja, todo o contexto social no qual as mulheres foram e estão inseridas foi criado e projetado por homens e para homens. É no momento de percepção deste fato que as mulheres passam a denunciar as diversas formas de opressão e a lutar pela tão sonhada igualdade de gênero.

Entretanto, ainda que, em momentos históricos mais recuados no tempo, não se possa falar, claramente, de um movimento social feminista, propriamente dito, mister tratarmos de atitudes pioneiras que preparavam o solo fértil da história para a eclosão desses diversos movimentos. Sendo assim, já no início do Renascimento, pode-se dizer que existiu a primeira ativista a lutar pelos direitos das mulheres: Christina de Pisan, que é considerada uma das primeiras feministas, por ter um discurso articulado e coerente na defesa dos direitos das mulheres, escrevendo aquele que seja talvez o primeiro livro feminista chamado de "Livre des trois vertus", escrito em 1405, onde expõe que homens e mulheres são iguais, já condenando a dupla moral pela qual o mesmo ato é crime, ou, pelo menos, imoralidade, quando é praticado por alguém do sexo feminino e não tem o mesmo peso se for praticado por alguém do sexo masculino. (ALVES, 2007, p. 18-19). 
Outro passo significativo se deu no auge da Revolução Francesa, no século XVIII, pois, precisamente no ano de 1791, Olympe de Gouges apresenta uma reivindicação eminentemente política: propõe a Declaração dos Direitos da Mulher, análoga à Declaração dos Direitos do Homem e do Cidadão; votada pela Assembleia Constituinte Francesa, no ano de 1789. Não se trata, aqui, porém,de discorrer sobre a Declaração dos Direitos dos Homens, dado à sua repercussão histórica, como um dos marcos fundantes do que se denomina de direito ocidental e/ou direitos individuais; mas basta ressaltar que seus 17 artigos inspiraram os 30 artigos da Declaração Universal dos Direitos Humanos, aprovada pela ONU, em 1948 e assinada por um grande número de nações, com o fim da II $^{\circ}$ Guerra e para restabelecer um novo patamar civilizatório de direitos.

Entretanto, cabe destacar que a Declaração proposta por Olympe também continha 17 artigos, marcando ainda mais sua intenção política e crítica ao documento, pois a referida ativista pretendia a abolição dos privilégios masculinos e garantia de direitos e deveres igualitários para as mulheres. Contudo, a Revolução estava sendo dirigida pela burguesia em ascensão, cujos interesses residiam, de um lado, na eliminação dos privilégios feudais; mas de outro, na manutenção do poder em mãos masculinas, uma vez que sequer se tratava de admitir o contrário, ou seja, a possibilidade real de participação política feminina nos rumos do novo regime.

Frustram-se, então, desta forma, os esforços de Olympe de Gouges, uma vez que ela é morta na guilhotina no ano de 1793. (GOUGES, 2007). Porém, a luta das mulheres não se encerrou neste momento. Outras feministas tentariam romper as barreiras colocadas à sua frente, combatendo a superioridade masculina através de jornais e clubes. Entretanto, os primeiros tem existência curta e os segundos são boicotados pelos clubes masculinos, consolidando assim, uma sociedade onde as mulheres permaneceriam sem espaço na vida política, inferiorizadas socialmente e, em posição subalterna no seio familiar, tendo ainda que competir em desigualdade de condições com os homens pelas mesmas oportunidades econômicas. (SAFFIOTI, 1976, p. 107).

Já na Europa, no inicio do século XIX, a mulher era tão ou mais explorada que os trabalhadores do sexo masculino, uma vez que o trabalho em domicílio era o que os ingleses chamam de sweating system ${ }^{3}$ : A operária trabalhava continuamente e não ganhava o suficiente para atender às suas necessidades. Assim, em 1831, por toda a Europa, mas,

\footnotetext{
${ }^{3}$ SWEATING SYSTEM: em tradução livre, "exploração patronal".
} 
sobretudo na Inglaterra, as funcionárias trabalhavam cerca de dezessete horas por dia, em locais sem as mínimas condições ditas humanas. Muitas delas tornavam-se tuberculosas antes de terminar a fase de aprendizagem. Além disso, as operárias eram abusadas pelos empregados do sexo oposto. (BEAUVOIR, 1970, p. 148-149).

Dessa forma, uma vez trazidos esses momentos de destaque das reivindicações femininas, importante ressaltar que, para compreender as dinâmicas desses movimentos sociais, é importante ressaltar que, embora não sejam lineares, no sentido de se sucederem uns aos outros, surgindo um movimento com o término do anterior, ressalta-se que, ao contrário, na verdade, eles coexistiram e coexistem, em suas reivindicações e princípios; só que, deve-se destacar que se formaram três ondas do movimento feminista,que nada mais são do que as gerações em que o movimento estava e está inserido. Dessa maneira se torna mais claro a forma a entender a organização e a reinvindicação de cada época.

Neste sentido, a primeira onda refere-se ao feminismo do século XIX, que foi um movimento liberal de luta pela igualdade de direitos civis, políticos e de educação. Foi neste momento que surgiram as primeiras denúncias de opressão masculina, bem como a reivindicação do direito ao voto. A segunda onda surgiu nas décadas de 60 e 70 do século XX, especialmente nos Estados Unidos e na França, onde o primeiro lutava pela igualdade entre os sexos, enquanto o segundo lutava para serem discutidas as diferenciações entre homens e mulheres, como forma de garantir a igualdade na diferença. Já a terceira onda, por fim, surgiu nos anos 80, igualmente do século XX e se mantém até o momento, com o intuito e consolidar o desafio de pensar simultaneamente as diferenças subjetivas entre homens e mulheres, bem como a igualdade de direitos. (FREITAG, 2015, p. 22-23).

Isto nos permite, por sua vez, a tratar dessa questão em nosso país, haja vista que no Brasil, na década de 40,o movimento feminista teve seu inicio com a Dra. Bertha Lutz,conhecida como a maior líder na luta pelos direitos políticos das mulheres brasileiras (SCHUMAHER, 2000, p. 106-112). Ela se empenhou pela aprovação da legislação que outorgou o direito das mulheres ao voto, bem como de serem votadas, inspirada em uma visita que fizera a Londres, antes da I Guerra Mundial, em um momento onde o feminismo inglês encontrava-se em uma de suas fases mais violentas. De volta ao Brasil, após concluir seus estudos, transforma-se na primeira mulher pregadora da emancipação da mulher no país 
e passa a representar o Brasil, juntamente com Olga de Paiva Meira4 no Conselho Feminino Internacional da Organização Internacional do Trabalho, em cuja primeira Conferência são aprovados, dentre outros, os seguintes princípios gerais: salário igual para ambos os sexos no mesmo trabalho e aplicação de leis e regulamentos para a proteção dos trabalhadores. (SAFFIOTI, 1976, p. 257).

Nos anos 50, o Brasil acompanhou, com o fim da Segunda Guerra, uma ascensão da classe média. Os brasileiros viam o país crescer e desenvolver a urbanização e a industrialização, e com elas, o aumento das possibilidades de educação e profissionalização de ambos os sexos. Os discursos políticos da época eram marcados por ideias fortalecidas de democracia e participação popular. A vida familiar sofreu modificações, as diferenças entre homens e mulheres diminuíram, mas as distinções de papel entre um e outro permaneceram bem evidentes; e embora o trabalho da mulher passasse a ser mais comum, ainda assim era visto como secundário, já que o homem ainda era o chefe da casa. Porém, com o fim do conflito, desenvolveu-se a ideologia de que as mulheres deveriam voltar ao lar e aos seus valores tradicionais, porque já haviam participado do esforço de guerra, de forma que sua contribuição deveria se voltar novamente para o lar. Evidentemente, o Brasil acabou sendo influenciado por esse discurso.

Assim, naquilo que se reconhece como família modelo da época, os homens detinham autoridade sobre a família e eram responsáveis por seu sustento. A mulher, tida como ideal, era aquela que se adaptava aos padrões femininos tradicionais, com ocupações que giravam em torno do lar, instinto materno, pureza, resignação, cuidado com o marido e os filhos, tendo sua vida sexual restringida, enquanto a moralidade masculina era favorecida, já que as regras conjugais não eram tão rígidas para eles com relação às suas aventuras eróticas. (BASSANEZI, 2001, p. 608-609).

Portanto, é na segunda metade do século XX que o feminismo se consolida como movimento de luta de mulheres, lutas que surgem a partir do reconhecimento da opressão sistemática de que são vítimas. Estes movimentos acreditam que as relações humanas não são naturais e, sim, sociais e, portanto, são passíveis de transformação. As reivindicações surgem da afirmação dos direitos iguais e a partir da realidade tão desigual de poderes entre homens e mulheres. (APFELBAUM, 2009, p. 144-145).

\footnotetext{
${ }^{4}$ OLGA DE PAIVA MEIRA: Feminista e ativista política, nasceu em São Paulo (SP), representou o Brasil no Conselho Feminino Internacional, em 1919. Participou de varias ações assistencialistas e da Revolução Constitucionalista de 1932, presidindo a Assistência às Famílias dos Combatentes.
} 


\section{A IMPORTÂNCIA DA LUTA DOS MOVIMENTOS FEMINISTAS NO DESENVOLVIMENTO DA TIPIFICAÇÃO DO FEMINICÍDIO E NA BUSCA POR IGUALDADE ENTRE OS GÊNEROS}

A década de 60 foi, então, o momento de consolidação dos valores femininos no mundo, sendo bastante marcante para o protagonismo da mulher, onde surgiu um movimento de rebeldia que dá origem às lideranças femininas. Para que seja possível entender o imaginário das mulheres e suas representações, nesta década, é necessário refletir sobre o significado de algumas ideologias e utopias. Neste sentido, são relevantes as lições de Lia Faria:

Dois pressupostos básicos impõem-se nesta reflexão: o de que os anos 60 significaram uma época de efervescência política que apontou para mudanças sociais, econômicas e culturais e o de que as mulheres da classe dominante, na sua maioria, brancas, foram as que se apropriaram mais rapidamente da informação (...). (FARIA, 1997, p. 16-17).

Foram, assim, três os principais fatores a influenciar radicalmente o movimento feminista a partir dos anos sessenta: $O$ controle de natalidade com o uso de pílula contraceptiva; a inclusão de muitas mulheres na área de produção e a liberdade cultural, que trouxe consigo a revolução sexual. Também cabe ressaltar que o movimento feminista cresceu com a ajuda e influência do movimento negro nos Estados Unidos, tanto quanto com o movimento hippie, que contestou os valores do capitalismo e do consumismo burguês, nesta mesma década, marcando, de forma indelével, a efervescência cultural e social do período (GUTIÉRREZ, 1985, p. 100).

Dessa maneira, corroborando com a verdadeira agitação da época, Dahl afirma que:

[...] O direito das mulheres integra-se no novo movimento feminista nascido nos Estados Unidos, nos meados dos anos 1960. Os movimentos feministas, pelo menos nos dois últimos séculos, têm estado sempre presentes na história, mas nunca assumiram uma dimensão tão vasta e profunda como o feminismo atual. (DAHL, 1993, p.13).

Estes grupos rebeldes multiplicaram-se, congregando as atividades em pontos comuns. Tais grupos surgiram primeiramente nos Estados Unidos, e logo após, na Europa, com muitas divergências entre eles, contudo há o enfoque em comum: $\mathrm{O}$ fato de lutar contra as desigualdades e violências que assolam as mulheres. (ALVES, 2007, p. 68-69). Agora, o corpo feminino é o centro das lutas travadas nesta nova onda feminista, que avança pelo século XXI, onde é reivindicada a autonomia sexual plena das mulheres. A partir deste momento, são organizadas grandes mobilizações em favor da possibilidade do abortamento e 
por legislações contra o estupro. Há, por toda a parte, uma necessidade de conquistar o direito ao controle da procriação, a livre disposição sobre o próprio corpo e, também, a recusa por tratar a violência como uma fatalidade pelo fato de ser mulher; e também a revolta por definições naturalizadas de divisão do trabalho por questões de gênero (LYPOVETSKI, 2000, p. 69).

No Brasil, as primeiras denúncias da violência que, continuamente, eram praticadas contra as mulheres, ocorreram entre os anos 70 e 80, em meio à abertura política, que teve como resultado um processo de redemocratização política e social do país. Neste contexto, os movimentos feministas tiveram intensa participação e sua mobilização buscou criar vias de diálogo com o Estado, denunciando a atuação do sistema de justiça e seus critérios, que absolviam homens que assassinavam suas companheiras, usando argumentos que justificavam e legitimavam o comportamento masculino. Foi denunciado ainda o descaso com as denúncias de violência sexual pelas delegacias e a falta de assistência às mulheres vítimas de violência. Para reverter o quadro, foram cobradas políticas públicas que punissem e erradicassem a violência contra as mulheres. Nesse sentido, entre as primeiras conquistas do movimento feminista no Brasil, destaca-se a criação de Delegacias de Defesa da Mulher, ainda hoje reconhecida como uma das principais políticas direcionadas para as mulheres em situação de violência. (PASINATO, 2008).

Em nível internacional, no ano de 1975, a Organização das Nações Unidas instaurou o Ano Internacional da Mulher. Assim, os temas pertinentes à mulher vieram com força: Violência sexual, cidadania, jornada de trabalho, abortamento, métodos contraceptivos, etc. (MATOS, 1997, p. 74). No Brasil, as comemorações do Ano Internacional da Mulher fizeram com que aumentasse significativamente o movimento de mulheres nos estados de São Paulo e Rio de Janeiro. Em 1976 esses grupos feministas que surgiram, criaram um jornal chamado "nós mulheres"; onde a maioria dos artigos tratava sobre política e condições de vida. Foi um marco na luta feminista no Brasil. (MORAES, 1997, p.144).

Pode-se, então, afirmar que foi através destas lutas das mulheres no mundo todo que, em 1977, um novo delito foi estabelecido nos Estados Unidos: O assédio sexual, que passa a ser reconhecidamente um problema social, e a ideia, antes predominante, de que a agressividade masculina é natural e irreprimível e toda a responsabilização recai sobre a mulher, começa a ruir. É neste momento que surge a ideia de punir para erradicar. (LYPOVETSKI, 2000, p. 79-83). 
Por conta das transformações sociais protagonizadas, tanto no meio econômico, quanto em relação ao foro íntimo da estrutura familiar e, mais intensamente ainda, nas relações sexuais, é que o movimento feminista é apontado, neste último século, como o maior fenômeno social. Esses fatos históricos, devidamente associados com esses movimentos sociais, entretanto, podem nos levar a crer que estes últimos estão concluídos em suas motivações, já que seus objetivos iniciais foram cumpridos e, podemos afirmar, com certeza, que as mudanças decorrentes desta luta são indiscutíveis. Contudo, a verdadeira consolidação só se dará quando estes direitos adquiridos e devidamente positivados em diversas legislações estiverem legitimados na subjetividade feminina. Logo, é, ainda, preciso que as mulheres reconheçam-se e sinta-se em igualdade de condições com os homens. (ZUWICK, 2000, p.38).

Por fim, é importante frisar que a igualdade tanto buscada pelas mulheres, é uma necessidade histórica e não de conveniência. Transferiram para as relações entre homem e mulher as mesmas relações presentes no sistema capitalista, que são as relações impostas por quem manda a alguém que deve obediência. Buscar esta igualdade significa o mesmo que libertar a mulher e fazê-la se sentir com os mesmos direitos dos homens, respeitando-a como ser humano idêntico ao homem na capacidade, na necessidade, no sentimento, nos direitos e deveres. (POSADAS, 1979, p. 127). A prova inequívoca de que se trata de um problema social grave são os números relativos a essa violência, já que, quando o assunto é violência contra a mulher, o Brasil é um dos primeiros nos rankings mundiais, demonstrando que o problema merece a devida atenção da sociedade e dos órgãos públicos, tanto quanto formas de combatê-lo, afinal, para eliminar um mal da sociedade é preciso que a mesma o reconheça como um mal.

\section{TIPIFICAÇÃO DO FEMINICÍDIO: ATO SIMBÓLICO, POLÍTICO E JURÍDICO}

Quando focamos nossa atenção na história dos institutos jurídicos em nosso direito pátrio, percebemos a ação do legislador, certamente fazendo eco a certos valores então dominantes em nossa sociedade, no sentido de categorizar e excluir ou diminuir a importância da mulher como sujeito ativo da vida social, tornando-a apenas sujeito passivo, limitando sua capacidade e apresentando diversas restrições aos seus direitos. Na vida cível, a capacidade feminina sempre foi restrita, pois o direito sempre agiu com a preocupação de limitar sua 
capacidade, sua educação e seu patrimônio, coibindo assim, seu poder de decisão no seio familiar. No Direito Penal, de forma geral, as mulheres sempre foram tidas como vítimas, frágeis, dependentes e que não ofereceriam risco nenhum à sociedade, não demandando, portanto, quaisquer tutelas penais específicas, nem punitivas, muito menos protetivas, já que todos os crimes praticados pelos homens contra as mulheres eram justificáveis dentro de uma lógica de dominação masculina. (MELLO, 2010).

Neste cenário, coube, desde sempre, ao Direito Penal categorizar quais mulheres cumpriam os requisitos de honestidade e poderiam se considerar vítimas e quais eram consideradas desonestas; e por isso, ao invés de vítima da situação, ela passa a ser a provocadora. Esta divisão entre honesta e desonesta e a própria diferenciação entre homens e mulheres, reproduzida pelo legislador, está tão presente na sociedade que ainda hoje tem ares de naturalidade. (MELLO, 2010). Utilizar justificativas como passionalidade ou paixão incontrolável para justificar um assassinato faz com que a violência de gênero seja banalizada, escondendo todo o sistema de dominação patriarcal existente até os dias de hoje. (CLADEM, 2012, p. 09). Em grande parte da legislação, essas diferenciações desapareceram ao longo dos anos, entretanto, a conduta cultural e social se manteve; e eliminar estas normas discriminatórias não foi o suficiente e por isso, leis específicas foram criadas, na tentativa de diminuir a violência contra a mulher.

É neste contexto que, em 09 de março de 2015, o Brasil se somou aos outros 15 países da América Latina, tipificando o termo Feminicídio, a partir de uma recomendação da Comissão Parlamentar Mista de Inquérito sobre Violência contra a Mulher, incluindo como uma qualificadora de crime hediondo, conforme texto da Lei 13.104, que alterou o Código Penal vigente no país. Vejamos:

Art. $1^{\circ} \mathrm{O}$ art. 121 do Decreto-Lei $\mathrm{n}^{\mathrm{o}}$ 2.848, de 7 de dezembro de 1940 - Código Penal, passa a vigorar com a seguinte redação:

"Homicídio simples

Art. 121. [...]

Homicídio qualificado

$\S 2^{\circ}[\ldots]$

Feminicídio

VI - contra a mulher por razões da condição de sexo feminino:

[...]

$\S 2^{\circ}$-A Considera-se que há razões de condição de sexo feminino quando o crime envolve:

I - violência doméstica e familiar;

II - menosprezo ou discriminação à condição de mulher.

Aumento de pena

$[\ldots]$

Revista de Gênero, Sexualidade e Direito| e-ISSN: 2525-9849 | Salvador | v. 4 | n. 1 | p. 80 - 98 | Jan/Jun. 


\title{
A IMPORTÂNCIA DA LUTA DOS MOVIMENTOS FEMINISTAS NO DESENVOLVIMENTO DA TIPIFICAÇÃO DO FEMINICÍDIO E NA BUSCA POR IGUALDADE ENTRE OS GÊNEROS
}

\begin{abstract}
$\S 7^{\circ}$ A pena do feminicídio é aumentada de $1 / 3$ (um terço) até a metade se o crime for praticado:

I - durante a gestação ou nos 3 (três) meses posteriores ao parto;

II - contra pessoa menor de 14 (catorze) anos, maior de 60 (sessenta) anos ou com deficiência;

III - na presença de descendente ou de ascendente da vítima. [...]. (BRASIL, 2015).
\end{abstract}

Conforme o disposto na Lei, Feminicídio é o homicídio cometido contra a mulher por razões de gênero, embora o termo gênero tenha sido substituído pela expressão "condição de sexo feminino", o que causou algumas dúvidas com relação à aplicabilidade da lei, conforme se poderá verificar a seguir. Importante frisar que o sujeito ativo da ação pode ser qualquer pessoa, entretanto a legislação é clara e expressa ao mencionar que somente mulheres podem figurar como agente passivo, o que causa a referida divergência a respeito do conceito, uma vez que a terminologia mulher pode ser compreendida de várias formas, ou seja, sob o enfoque biológico, ou, ainda, com foco nas questões psicológicas e até mesmo jurídicas. Então surge um impasse: Se a vítima for transexual, trata-se ainda assim de Feminicídio? (FERNANDES, 2015. p. 34).

Com relação a esta indagação, há três possibilidades de entendimento: a primeira é a corrente conservadora, que afirma que o transexual, geneticamente não é mulher, mesmo nos casos em que já houve intervenção cirúrgica, o que acarreta no descarte automático da proteção especial da lei; a outra corrente é mais liberal e entende ser possível garantir as proteções legais no caso de já ter sido realizado a cirurgia, sem possibilidade de alterações. (CUNHA, 2015). A terceira corrente, defendida por Greco, é atinente às questões e critérios jurídicos. Assim, para o autor:

[...] entendemos que o único critério que nos traduz, com a necessária segurança exigida pelo direito, e em especial o direito penal, é o critério que podemos denominar de jurídico. Assim, somente aquele que for portador de um registro oficial (certidão de nascimento, documento de identidade) onde figure, expressamente, o seu sexo feminino, é que poderá ser considerado sujeito passivo do feminicídio.

Aqui pode ocorrer que a vítima tenha nascido com o sexo masculino, sendo tal fato constado expressamente em seu registro de nascimento. No entanto, posteriormente, ingressando com uma ação judicial, vê sua pretensão de mudança de sexo atendida [...], passando a constar, agora, como pessoa do sexo feminino. Somente a partir deste momento é que poderá ser considerada como sujeito passivo do feminicídio. (GRECO, 2015). 
Neste sentido, necessário é analisar o posicionamento do Supremo Tribunal de Justiça, que tem consolidado seu posicionamento, garantindo amparo legal para o transexual operado, de forma que o mesmo obtenha autorização judicial para adequar seus documentos à sua nova condição física, o que o torna, por conseguinte, sujeito passivo da qualificadora do delito de Feminicídio. Vejamos decisão do Superior Tribunal de Justiça:

\author{
REGISTRO PÚBLICO. MUDANÇA DE SEXO. EXAME DE MATÉRIA \\ CONSTITUCIONAL. \\ IMPOSSIBILIDADE DE EXAME NA VIA DO RECURSO ESPECIAL. \\ AUSÊNCIA DE \\ PREQUESTIONAMENTO. SUMULA N. 211/STJ. REGISTRO CIVIL. \\ ALTERAÇÃO DO \\ PRENOME E DO SEXO. DECISÃO JUDICIAL. AVERBAÇÃO. LIVRO \\ CARTORÁRIO.
}

1. Refoge da competência outorgada ao Superior Tribunal de Justiça apreciar, em sede de recurso especial, a interpretação de normas e princípios de natureza constitucional.

2. Aplica-se o óbice previsto na Súmula n. 211/STJ quando a questão suscitada no recurso especial, não obstante a oposição de embargos declaratórios, não foi apreciada pela Corte a quo.

3. O acesso à via excepcional, nos casos em que o Tribunal a quo, a despeito da oposição de embargos de declaração, não regulariza a omissão apontada, depende da veiculação, nas razões do recurso especial, de ofensa ao art. 535 do CPC.

4. A interpretação conjugada dos arts. 55 e 58 da Lei n. 6.015/73 confere amparo legal para que transexual operado obtenha autorização judicial para a alteração de seu prenome, substituindo-o por apelido público e notório pelo qual é conhecido no meio em que vive.

5. Não entender juridicamente possível o pedido formulado na exordial significa postergar o exercício do direito à identidade pessoal e subtrair do indivíduo a prerrogativa de adequar o registro do sexo à sua nova condição física, impedindo, assim, a sua integração na sociedade.

6. No livro cartorário, deve ficar averbado, à margem do registro de prenome e de sexo, que as modificações procedidas decorreram de decisão judicial.

7. Recurso especial conhecido em parte e provido. (BRASIL, 2009).

Trata-se, assim, de decisão emblemática, não apenas em função de que trata da questão específica de transexual, mas, principalmente, por abordar, claramente, a questão do feminicídio. Entretanto, apesar desta divergência quanto à letra da lei, a medida teve grande repercussão nacional, considerada um grande avanço político, legislativo e social, fruto de reinvindicações do movimento feminista há mais de 50 anos. Para estes movimentos sociais, dar nome ao crime motivado pelo ódio, demonstração de posse e misoginia não é somente com o intuito de dar visibilidade ao problema, mas também criar e aprimorar rotinas de investigação e julgamento, com a finalidade de colher dados e investigar, tanto na esfera privada como na pública, os assassinatos, prevenir e coibi-los, pela aplicação da devida penalidade. (ONU, 2015). 
O levantamento destes dados é importante para auxiliar na captação de informação e elaboração de políticas públicas com o objetivo de combater esta forma extrema de violência. Faz-se mister mencionar que a Lei não terá impacto tangível apenas por meio de sentenças, mas também pela forma como for incorporada no cotidiano, por meio de campanhas e debates, como ocorreu com a Lei Maria da Penha, introduzindo-a no seio da sociedade. Importante salientar que, apesar deste avanço histórico, o entendimento do que é considerado Feminicídio pelo Estado ainda é problemático, uma vez que esta classificação requer mais estudo e investigação. Por exemplo, um sequestro ou um tráfico de pessoas, que resulte em morte, pode estar atrelado a uma forte relação de gênero, que passou despercebida na sociedade, bem como pelos operadores do Direito. (BRASIL, 2013).

Ao tipificar o Feminicídio, foi reconhecido, na forma da Lei, que as mulheres morrem por serem mulheres, expondo um problema social severo que é a constante e histórica desigualdade de gênero, que persiste na sociedade. Sancionar esta lei é uma vitória social, que combate a impunidade, impedindo que feminicidas sejam beneficiados por interpretações jurídicas moralmente inaceitáveis, mas juridicamente possíveis, como a hipótese de crime passional, em que o homem mata por amor. Trata-se, portanto, de uma forma de proteger a vida e a dignidade da pessoa humana. (BRASIL, 2013). Dar visibilidade ao termo feminicídio, considerando seu valor histórico, contribui para abrir espaço para a discussão não só dos homicídios de mulheres praticados por companheiros ou ex-companheiros como também destaca os assassinatos de mulheres, socialmente vulneráveis, tais como as que exercem a prostituição. (CLADEM, 2012).

Apesar de todo o exposto e da receptividade positiva da Lei, ainda é possível encontrar posicionamento contrário à efetiva necessidade da tipificação em comento, por acreditar-se que a qualificadora do Feminicídio fere o princípio Constitucional da Igualdade, uma vez que trata a morte de mulheres de forma diferenciada da morte de homens. Todavia, assim como a Lei Maria da Penha tratou de forma diferenciada a violência doméstica por ter o legislador compreendido que há desigualdade de gênero no âmbito doméstico; no feminicídio esta questão é apenas ampliada para todos os setores, tanto públicos, como privados, uma vez que a desigualdade existe, faltava tão somente nomeá-la. (CAMPOS, 2015).

Fazendo uma breve análise do princípio da igualdade historicamente, é possível afirmar que este foi o responsável pela criação dos sistemas universais no que tange aos 
direitos entre homens e mulheres, uma vez que surgiu com o intuito de pontuar as diferenças imaginárias entre homens e mulheres, contribuindo com a luta pela liberdade feminina, uma vez que reconhecer todos os direitos como sendo também das mulheres significa fazer com que se adaptem às normas masculinas, tornando as demandas de suas diferenças com relação aos homens, tais como a maternidade, como um regime de exceção, o qual as caracteriza e trata como se fossem homens imperfeitos (APFELBAUM, 2009, p. 116). É neste aspecto que se tornam fundamentais legislações específicas para o sexo feminino.

Analisando frente à constitucionalidade do princípio da igualdade, compreende-se que o mesmo não é violado com a tipificação do feminicídio, uma vez que a nova qualificadora trata a morte de mulher de forma diferenciada porque a mulher é exposta a relações diferenciadas e o papel do direito é atuar nestas particularidades, buscando construir uma sociedade igualitária, uma vez que homens e mulheres não são idênticos e observar e respeitar as particularidades de cada um é necessário, a fim de se aplicar, com sabedoria, o referido princípio, para que seja possível alcançar um ideal democrático onde todos sejam verdadeiramente iguais. (PAES, 2015; MENDONÇA, 2016).

Outras objeções foram feitas ao texto, como a crítica ao aumento da pena quando o delito ocorrer nos três primeiros meses posteriores ao parto. Entretanto, críticas como esta ignoram as diferenças biológicas cruciais entre homens e mulheres, especialmente nos primeiros meses após o parto e tal diferença não foi ignorada pelo legislador, que considerou tais aspectos. As críticas contra a lei carecem de fundamentação, uma vez que há, no mundo todo, estudos que reconhecem a diferença do homem e da mulher decorrentes de um sistema patriarcal, que dominou e domina ainda certas sociedades (SABADELL, 2016). Neste aspecto, tipificar tal crime foi a forma aparentemente encontrada para descobrir o véu de uma realidade até então não reconhecida pelo Direito Penal, numa tentativa de responder aos anseios da sociedade e dos órgãos internacionais de proteção aos direitos humanos, como visto anteriormente.

\section{CONSIDERAÇÕES FINAIS}

É reconhecidamente problemática, contudo, a não capacidade preventiva de nenhuma conduta ilícita, em razão das causas punitivas do Código Penal. Porém, deixar o crime de violência contra a mulher apenas como uma problemática social seria uma maneira de 


\section{A IMPORTÂNCIA DA LUTA DOS MOVIMENTOS FEMINISTAS NO DESENVOLVIMENTO DA TIPIFICAÇÃO DO FEMINICÍDIO E NA BUSCA POR IGUALDADE ENTRE OS GÊNEROS}

banalizá-lo e torná-lo um simples crime passional, como normalmente é divulgado na mídia, o que significa que promover a visibilidade do termo, ainda que por meio de medidas punitivas, é uma forma de conhecer e reconhecer a real magnitude do problema, com o objetivo de que se criem políticas públicas, no intuito de erradicar o problema, bem como se crie um sistema judicial realmente preparado e sensibilizado para julgar as questões de gênero.(MELLO, 2016).

Para que a Lei em comento deixe, entretanto, de ser somente simbólica, é necessário que se realize uma mudança estrutural no padrão de comportamento e mentalidade da sociedade como um todo, de forma que a cultura patriarcal seja completamente superada, uma vez que, ao desconstruir a ideia machista e sexista da sociedade, a mulher terá condições de lutar por espaço e representatividade de forma igualitária, saindo da situação de vulnerabilidade e subjugação na qual se encontra atualmente, sendo esta a fórmula encontrada para que se atinja a tão falada Igualdade prevista na Constituição Federal. (MENDONÇA, 2016).

Por todo o exposto, a tipificação do Feminicídio inicia um novo marco, em que o combate à violência de gênero, em suas mais diversas formas, é cada vez mais discutida e é nesta seara que a inclusão do termo no sistema jurídico brasileiro faz-se tão importante. Todavia, importante ressaltar que, embora o texto seja subjetivo e que por isso diversas interpretações possam ser feitas, algumas questões controversas poderiam ter sido evitadas, a fim de garantir uma melhor aplicabilidade da regra em comento, tal como a questão dos transexuais, que dependerão do entendimento do juiz para ter garantida sua proteção legal e, neste sentido, fica evidenciado o necessário investimento em sensibilização dos operadores de direito. Todavia, mesmo com algumas contradições e dúvidas, a tipificação do feminicídio é, em linhas gerais, muito mais positiva, pois abre a possibilidade de gradualmente inserir essa discussão nos âmbitos públicos, iniciando de fato a luta contra o homicídio de mulheres por razões de gênero. (MELLO, 2016).

Tendo sempre presente o movimento dialético que se estabelece entre a dinâmica social e a produção legislativa, ou as respostas legais do direito às demandas sociais, entendemos que, em inúmeras vezes, o legislador se mantém aquém dessas reivindicações, até mesmo pela própria maneira específica de se tornarem válidas as leis, via processos legislativos específicos. O mesmo se pode dizer em relação às decisões judiciais. Entretanto, 
em outros momentos, ocorre o contrário, ou seja, aquilo que se denomina de protagonismo, em se tratando dessas últimas, ou então, de uma postura de vanguarda do legislador, ao estabelecer, legalmente, direitos que parecem estar em dissintonia com, pelo menos a maioria desses valores sociais instituídos. Entretanto, pretendemos afirmar que, como já mencionado anteriormente, a tipificadora não tenha, isoladamente, o condão de pôr um fim a essas práticas; e ainda que significativos setores de nossa sociedade precisem adaptar-se a essa nova postura legislativa e judicial, agora, pelo menos, dispomos de uma definição legal clara quanto ao que fazer em casos que se enquadrarem nessas disposições. Assim, além da clara percepção do problema, dispomos, agora, em nosso sistema legal, de um mecanismo forte para, juridicamente, nos lançarmos ao enfrentamento do problema.

\section{REFERÊNCIAS}

ALVES, Branca Moreira; PITANGUY, Jacqueline. O que é feminismo. São Paulo: Brasiliense, 2007 (Coleção Primeiros Passos).

APFELBAUM, Erika. Dominação. In: HIRATA, Helena; et al (Orgs.). Dicionário Crítico do feminismo. São Paulo: Ed. UNESP, 2009.

BASSANEZI, Carla. Mulheres nos anos dourados.In: PRIORI, Mary Del (Org.). História das Mulheres no Brasil. São Paulo: Contexto 2001.

BEAUVOIR, Simone de. O segundo sexo: fatos e mitos. São Paulo: Difusão europeia do livro, v.1, 1970. (ebook).

BRASIL. Presidência da República. Lei 13.104 de 09 de março de 2015.

Altera o art. 121 do Código Penal, para prever o feminicídio como circunstância qualificadora do crime de homicídio, e o art. $1^{\circ}$ da Lei $\mathrm{n}^{\mathrm{o}}$ 8.072, de 25 de julho de 1990, para incluir o feminicídio no rol dos crimes hediondos. Disponível em: <http://www.planalto.gov.br/ ccivil_03/_Ato2015-2018/2015/Lei/L13104.htm>. Acesso em: 10 mai. 2016.

BRASIL. Senado Federal. Comissão Parlamentar Mista de Inquérito. Relatório Final. Brasília, junho de 2013.. Disponível em: <http://www.senado.gov.br/atividade/ materia/getPDF.asp?t=130748\&tp=1>. Acesso em: 10 mai. 2016.

BRASIL. Superior Tribunal de Justiça. RECURSO ESPECIAL: REsp 737993 MG 2005/00486064. Relator: João Otávio de Noronha. Data do Julgamento: 10 nov. 2009.Disponível em: <http://stj.jusbrasil.com.br/jurisprudencia/8634072/recurso-especialresp-737993-mg-2005-0048606-4-stj>. Acesso em: 16 mai. 2016.

CAMPOS, Carmen Hein de. Violência, crime e Segurança Pública: Feminicídio no Brasil uma análise crítico-feminista. Revista Eletrônica da Faculdade de Direito - PUCRS. Porto 


\section{A IMPORTÂNCIA DA LUTA DOS MOVIMENTOS FEMINISTAS NO \\ DESENVOLVIMENTO DA TIPIFICAÇÃO DO FEMINICÍDIO E NA BUSCA POR \\ IGUALDADE ENTRE OS GÊNEROS}

Alegre, v. 7, n.1, p. 103-115, Jan./Jun. 2015. Disponível em:

$<$ http://revistaseletronicas.pucrs.br/ojs/index.php/sistemapenaleviolencia/article/view/20275/1

3455>. Acesso em: 12 mai. 2016.

COMITÉ DE AMÉRICA LATINA Y EL CARIBE PARA LA DEFENSA DE LOS

DERECHOS DE LA MUJER (CLADEM). Contribuições ao debate sobre a tipificação

penal do Feminicídio/Femicídio. Lima, jun. 2012, p. 09. Disponível em:

<http://www.compromissoeatitude.org.br/wp-content/uploads/2013/10/CLADEM_

TipificacaoFeminicidio2012.pdf>. Acesso em: 10 mai. 2016.

CUNHA, Rogério Sanches. Pode figurar como vítima do feminicídio pessoa transexual? 14 de março 2015. Disponível em: <https://www.cers.com.br/noticias-e-blogs/noticia/podefigurar-como-vitima-do-feminicidio-pessoatransexual;jsessionid=DOp+zd7

GydQD0GcJ4zqq1Jtq.sp-tucson-prod-10>. Acesso em: 12 mai. 2016.

DAHL, Tove Stang. O direito das mulheres: Uma introdução à teoria do direito feminista. Lisboa: Fundação Calouste Gulbenkian, 1993.

FARIA, Lia. Ideologia e utopia nos anos 60: um olhar feminino. Rio de Janeiro: EdUERJ, 1997.

FERNANDES, Valéria Diez Scarance. Lei Maria da Penha: o processo penal no caminho da efetividade. São Paulo: Atlas, 2015. (E-book).

FREITAG, Raquel Ko. (Re) discutindo Sexo/gênero na sociolinguística. In: FREITAG, Raquel Ko; SEVERO, Cristine Gorski (orgs). Mulheres, linguagem e poder: Estudos de gênero na sociolinguística brasileira. São Paulo: Editora Edgard Blucher, 2015.

GOUGES, Olympe de. Declaração dos Direitos da Mulher e da Cidadã. Traduzido e apresentado por Selvino José Assmann. Revista Internacional Interdisciplinar Interthesis, v.4, n. 1, jan./jun. 2007. Disponível em: <https://periodicos.ufsc.br/ index.php/interthesis/article/viewFile/911/10852>. Acesso em: 23 nov. 2015.

GRECO, Rogério. Feminicídio. Comentário sobre a lei nº 13.104, de 09 de março de 2015. 14 de março de 2015. Disponível em: <http://www.rogeriogreco.com.br/?p=2906>. Acesso em: 10 mai. 2016.

GUTIÉRREZ, Rachel. O feminismo é um humanismo. Rio de Janeiro: Edições Antares; São Paulo, Nobel, 1985.

LYPOVETSKI, Gilles. A terceira mulher: permanência e revolução do feminino. Tradução de Maria Lucia Machado. São Paulo: Companhia das Letras, 2000.

MATOS, Maria Izilda S. de. Gênero e história: Percursos e possibilidades. In: Gênero sem fronteiras: Oito olhares sobre mulheres e relações de gênero. Mônica Raisa Schpun (org). Florianópolis: Editora Mulheres, 1997. 
MELLO, Adriana Ramos de. Feminicídio: uma análise sociojurídica do fenômeno no Brasil. Revista da EMERJ. Rio de Janeiro, v. 19, n. 72, p. 140-167, jan./mar. 2016. Disponível em: <http://bdjur.stj.jus.br/jspui/handle/2011/100615>. Acesso em: 07 jun. 2016.

MELLO, Marilia Montenegro Pessoa de. Da mulher honesta à Lei com nome de mulher: O lugar do feminismo na legislação penal brasileira. Revista Videre. Dourados, ano 2, n. 3, p. 137-159, Jan./Jun. 2010. Disponível em: <http://www.periodicos.ufgd.edu.br/index.php/ videre/article/viewFile/885/pdf_27>. Acesso em: 10 mai. 2016.

MENDONÇA, Amanda Pereira. Constitucionalidade de medidas afirmativas às mulheres. A desigualdade de gêneros como pressuposto da limitação ao acesso à justiça às mulheres.

Revista Jurídica Luso Brasileira. [S.L.], ano 2, n. 3, p. 59-79, 2016. Disponível em: <http://www.cidp.pt/publicacoes/revistas/rjlb/2016/3/2016_03_0059_0079.pdf>. Acesso em: 05 jun. 2016.

MORAES, Maria Lygia Quartim de. O feminismo e a vitória do neoliberalismo. In: SCHPUN, Mônica Raisa (org). Gênero sem fronteiras: Oito olhares sobre mulheres e relações de gênero. Florianópolis: Editora Mulheres, 1997,p.144.

ORGANIZAÇÃO DAS NAÇÕES UNIDAS (ONU). Aprovação de projeto de lei do Feminicídio é avanço para enfrentar aumento de assassinato de mulheres. [S.L.], 04 de março de 2015. Disponível em: <http://www.onumulheres.org.br/?noticias=aprovacao-doprojeto-de-lei-do-feminicidio-e-avanco-para-enfrentar-aumento-de-assassinatos-de-mulheresdiz-onu-mulheres-brasil>. Acesso em: 10 mai. 2016.

PAES, Mariana Armond Dias. Inclusão do Feminicidio no Código Penal é uma questão de Igualdade e gênero. Consultor Jurídico (Conjur). [S.L.], 10 jan. 2015. Disponível em: $<$ http://www.conjur.com.br/2015-jan-10/mariana-paes-feminicidio-questao-igualdadegenero>. Acesso em: 05 jun. 2016.

PASINATO, Wânia. Violência contra as mulheres e Legislação Especial, ter ou não ter? Eis uma questão. Revista Brasileira de Ciências Criminais. v. 70, 2008. p. 321 - 360, Jan Fev., 2008. Doutrinas Essenciais Família e Sucessões. v. 1. p. 777 - 809, Ago., 2011.Disponível em:<http://www.revistadostribunais.com.br/maf/app/widgetshomepage/ resultList/document $\&$ src $=$ rl\&srguid=i0ad6007a000001508cf43c $2 \mathrm{acb} 62822 \mathrm{f} \&$ docguid=I335 $33 \mathrm{fc0f} 25511 \mathrm{dfab} 6 \mathrm{f} 010000000000 \&$ hitguid $=$ I33533fc0f $25511 \mathrm{dfab} 6 \mathrm{f0} 10000000000 \&$ spos $=1$ \&epos=1\&td=1361\&context=113\&startChunk=1\&endChunk=1>Acesso em: 21 out. 2015.

POSADAS, J. A libertação da mulher, a luta de classes e a Revolução Socialista. In: MACHEL, Samora (Org.). A libertação da mulher. São Paulo: Global Editora, 1979.

SABADELL, Ana Lucia. Violência Contra a Mulher e o Processo de Juridificação do Feminicídio. Reações e Relações Patriarcais no Direito Brasileiro. Revista EMERJ. Rio de Janeiro, v. 19, n. 72, p. 168-190, mar. 2016. Disponível em: <http://bdjur.stj.jus.br/jspui/ bitstream/2011/100601/violencia_contra_mulher_sabadell.pdf $>$. Acesso em: 06 jun. 2016.

SAFFIOTI, Heleieth I.B. A mulher na sociedade de classes: mito e realidade. Petrópolis, RJ: Editora Vozes, 1976. 
SCHUMAHER, Schuma; BRAZIL, Érico Vital(org). Dicionário Mulheres do Brasil: De 1500 até a atualidade.Biográfico e Ilustrado - Rio de Janeiro: Jorge Zahar, 2000.

ZUWICK, Ana Maria. Emancipação feminina: obstáculos e perspectivas para sua construção In: STREY, Marlene Neves; et al (Org.). Construções e perspectivas em gênero. São Leopoldo: Ed. Unisinos, 2000, p.38. 